\title{
Carta de potencial de erosão acelerada como ferramenta para o ordenamento territorial
}

\author{
Accelerated erosion chart for watershed spatial planning
}

Valdir Aparecido Galiano ${ }^{1}$, Reinaldo Lorandi², Franciane Mendonça dos Santos ${ }^{3}$ e José Augusto de Lollo 4

1 Universidade Presbiteriana Mackenzie, Escola de Engenharia Civil, Rua da Consolação, 930, São Paulo (Brasil), va.galiano@gmail.com.

ORCID: https://orcid.org/0000-0002-0413-4669

2 Programa de Pós-graduação em Engenharia Urbana, Universidade Federal de São Carlos. Rod. Washington Luís, km 235 - SP-310, CEP 13565-905, São Carlos, Brasil. E-mail: lorandir@gmail.com

ORCID: https://orcid.org/0000-0003-0026-7269

3 Programa de Pós-graduação em Engenharia Urbana, Universidade Federal de São Carlos. Rod. Washington Luís, km 235 - SP-310, CEP 13565-905, São Carlos, Brasil. E-mail: fran.mendonca@ hotmail.com.

ORCID: https://orcid.org/0000-0002-8506-2731

4 Programa de Pós-graduação em Engenharia Civil, Universidade Estadual Paulista - UNESP. Alameda Bahia, 550, CEP 15385-000, Ilha Solteira, Brasil. E-mail: jose.lollo@unesp.br.

ORCID: https://orcid.org/0000-0002-6703-5377

\begin{abstract}
Resumo: As atividades antrópicas em conjunto com a falta de planejamento do uso e conservação, podem ocasionar processos de degradação ambiental, como processos erosivos, assoreamento de corpos hídricos, inundações, entre outros, comprometendo a qualidade do meio ambiente, especialmente dos recursos hídricos. O trabalho teve por objetivo avaliar melhores alternativas de intervenção em relação aos processos de erosão acelerada na bacia hidrográfica do Ribeirão das Pedras (São Paulo, Brasil), integrando informações geotécnicas e de outras áreas de conhecimento. A bacia estende-se por $111,47 \mathrm{~km} 2$, tendo a maior parte de sua área no município de Santa Cruz das Palmeiras e parcelas menores nos municípios de Tambaú, Pirassununga e Porto Ferreira. A metodologia utilizada se baseou em Pejon (1992) e Pejon e Zuquette (2001) para elaborar uma Carta de Escoamento Superficial Potencial e a determinação de índice de erodibilidade dos materiais inconsolidados, associado a outras características geotécnicas, segundo Pejon e Zuquette (1993). Os resultados mostram forte influência dos materiais inconsolidados e dos usos da terra no potencial erosivo, e indicam que tais feitos podem ser amenizados com ações do poder público local e estadual, com políticas adequadas de uso e ocupação.
\end{abstract}

Palavras-chave: Bacia hidrográfica. Cartografia temática. Geologia ambiental.

\begin{abstract}
Anthropic activities, together with the lack of planning for land use and conservation, can cause processes of environmental degradation, such as erosion, siltation of water bodies, flooding, among others, compromising the quality of the environment, especially water resources. The objective of this paper was to evaluate better intervention alternatives in relation to accelerated erosion processes in the Ribeirão das Pedras watershed (São Paulo, Brazil), integrating geotechnical information and other knowledge areas. The river basin extends over $111.47 \mathrm{~km} 2$, with most of its area in the municipality of Santa Cruz das Palmeiras and smaller areas in the municipalities of Tambaú, Pirassununga and Porto Ferreira. The methodology used was based on Pejon (1992) and Pejon e Zuquette (2001) to elaborate a Potential Surface Flow Chart and the determination of the erodibility index of unconsolidated materials, associated with other geotechnical characteristics, according to Pejon e Zuquette (1993). The results show a strong influence of unconsolidated materials and land uses on the erosive potential, and indicate that such actions can be mitigated by actions of the local and state government, with appropriate land use policies.
\end{abstract}

Keywords: Watershed. Thematic cartography. Environmental geology.

\section{INTRODUÇÃO}

O desenvolvimento das diversas atividades antrópicas, envolvendo componentes do meio físico e o processo de ocupação do solo, em conjunto com a falta de planejamento de seu uso e conservação, pode 
desencadear, na maioria dos casos, processos de degradação ambiental, como erosões, assoreamento de corpos hídricos, inundações, entre outros, comprometendo a qualidade do meio ambiente, especialmente dos recursos hídricos (YANG et al. 2009) e aumentando a vulnerabilidade dos ecossistemas (KEMP, 1992, VITOUSEK et al., 1997; FOLLEY et al., 2005).

Desta forma, a degradação ambiental global se aproxima, cada vez mais, dos limiares de um colapso ecossistêmico (MILLENNIUM ECOSYSTEM ASSESSMENT, 2005), que associado a modificação dos recursos da terra e da água, ameaçam a qualidade dos solos, a biodiversidade e os recursos hídricos (FAO, 2011; WWAP, 2015).

O desenvolvimento sustentável deve ser subsidiado por informações do meio físico, pertinentes a diversas áreas do conhecimento, como a geologia, a ciência do solo, a hidrogeologia, a geomorfologia, entre outras. O Mapeamento Geotécnico é a técnica que reúne informações de diversas áreas para elaborar um produto final útil ao planejamento.

Dentre os processos de degradação do solo, a erosão é sem dúvida aquela que mais impactos tem gerado nos solos e na disponibilidade e qualidade dos recursos hídricos, requerendo intervenções para previsão e controle, de forma a evitar graves danos ambientais, desde a remoção de camada agricultável do solo até enchentes e perda de qualidade em mananciais superficiais e subterrâneos (GUPTA; AHMAD, 1996; LOURES et al., 2002; PIMENTEL, 2006; HE et al., 2006; FRANZ, 2011).

A erosão acelerada do solo propicia o aparecimento de sulcos, ravinas e voçorocas ocasionando a perda de solo e transporte de nutrientes, o que afeta a produtividade e a segurança alimentar, provoca poluição difusa e o assoreamento nos cursos d'água, reduzindo a vida útil dos reservatórios (Da Silva et al., 2013; Vente et al., 2013; Zhao et al., 2013). Assim, a meta do ordenamento territorial é compatibilizar as políticas com as condições do espaço, evitando conflitos (OLIVEIRA, 2010).

O advento das técnicas de geoprocessamento (BIELENKI; BARBASSA, 2012) tornou mais eficiente o levantamento e a análise de dados geotécnicos, e mais efetiva sua disponibilização aos órgãos públicos estaduais e municipais, para auxiliar no planejamento do uso e ocupação do solo.

Assim, a análise dos atributos geotécnicos, associada às informações de outra natureza (relevo, uso e cobertura, por exemplo), permite a escolha de melhores alternativas de intervenção na área. $\mathrm{O}$ trabalho apresenta a obtenção da carta de potencial de erosão a partir de dados geotécnicos para a bacia hidrográfica do ribeirão das Pedras (SP) para fins de uso no planejamento territorial.

\section{CARACTERIZAÇÃO DA ÁREA DE ESTUDO}

A bacia hidrográfica do Ribeirão das Pedras (BHRP) localiza-se na região centro-leste do Estado de São Paulo e faz parte da Unidade de Gerenciamento de Recursos Hídricos do Rio Mogi Guaçu - UGRH 9. Compreendendo uma área de drenagem de $111,37 \mathrm{~km}^{2}$, essa bacia de quarta $\left(4^{\mathrm{a}}\right)$ ordem (STRAHLER, 1952) com padrão de drenagem dendrítica (CHRISTOFOLETTI, 1974), tem como coordenadas (UTM) extremas: nascente (NO) - W252383,279 m, S7590710,299 m; nascente (NE) - W262962,400 m, S7591473,888 m e foz - W252545,067 m e S7578471,073 m, fuso 23.

Segundo informações emitidas por São Paulo - FEHIDRO (2011), o território brasileiro se mostra definido em Regiões Hidrográficas estabelecidas pela Resolução no 32 do Conselho Nacional de Recursos Hídricos de 15 de outubro de 2003, a qual definiu a divisão hidrográfica nacional. Na caracterização em nível federal, a bacia hidrográfica do rio Mogi Guaçu pertence à Região Hidrográfica do Paraná, a qual é constituída pela bacia hidrográfica do rio Paraná.

No Estado de São Paulo, a bacia hidrográfica do rio Mogi Guaçu (UGRHI-09) localiza-se na região nordeste do Estado. Essa UGRHI apresenta limites com as UGRHI's: Piracicaba/Capivari/Jundiaí; Tietê/Jacaré; Tietê/Batalha; Turvo/Grande; Baixo Pardo/Grande e Pardo.

A Bacia Hidrográfica do Rio Mogi Guaçu foi subdividida, em 1995, em compartimentos econômicoecológicos no "Macrozoneamento das Bacias dos Rios Mogi Guaçu, Pardo e Médio-Grande" (IG, 1995), sendo, em 2008, readequados, objetivando facilitar o planejamento e as ações dentro destes compartimentos. Desse modo foram realizados ajustes dos limites do compartimento Alto Mogi para que represente o trecho crítico da bacia, no qual é desenvolvido o Projeto Estiagem, coordenado pela CETESB (Regional 
Pirassununga). E também foram alterados os limites entre o compartimento Médio Mogi (antigo Médio Mogi Superior) e o Baixo Mogi (Antigo Médio Mogi Inferior) para que os seus limites coincidissem com os divisores de água dos principais afluentes do rio Mogi Guaçu daquelas áreas.

Uma das sub-bacias dessa UGRHI é a do Ribeirão das Pedras, que está toda inserida no compartimento Médio Mogi Superior e está classificado como um curso d’água classe 2. Segundo Feitosa (2008), essa bacia hidrográfica encontra-se localizada na Província Hidrogeológica da Bacia do Paraná, caracterizada por apresentar valores de capacidade específica acima de $10 \mathrm{~m}^{3} / \mathrm{h} \cdot \mathrm{m}$ e no subdomínio Bacia do Paraná (2Pr), caracterizado por apresentar muita alta a média favorabilidade hidrogeológica (incluem as principais unidades aquíferas da bacia sedimentar, representadas pelas formações Botucatu, Pirambóia, Guará, Caiuá, Bauru, Furnas).

Na distribuição das águas subterrâneas no Estado de São Paulo (ROCHA, 2005), se observa que a bacia hidrográfica ocorre em área dos aquíferos Guarani (aflorante) e Serra Geral Intrusivas.

A partir da interpretação de imagens de satélite feita por Oliveira (1995) e por trabalhos de campo realizados por Torezan (2000), foram identificadas as formações vegetais remanescentes, levando o autor a propor a criação da APA de Descalvado, e de formações de cerrado (cerradão e cerrado "senso estrito"), mata mesófila (floresta estacional semi-decidual) e mata ciliar. Esses remanescentes se encontram dispersos em manchas isoladas no meio da matriz de ocupação agrícola, onde a maior reserva atinge cerca de 1000 hectares.

Segundo a divisão geomorfológica do Estado de São Paulo (ROSS; MOROZ, 1997), a área de estudo localiza- Unidade Morfoestrutural Bacia Sedimentar do Paraná, com a maior parte de sua área situada na Unidade Morfoescultural do Planalto Ocidental Paulista e uma menor porção abrangendo a Unidade Morfoescultural da Depressão Periférica Paulista.

Tal morfoescultura, segundo esses autores, mostra-se representada na área pela unidade morfológica denominada Planalto Residual de São Carlos, tendo uma pequena porção inserida sobre a unidade morfoescultural denominada Patamares Estruturais de Ribeirão Preto, as quais podem ser assim descritas: dentro do Planalto Ocidental Paulista tem-se o Planalto Residual de São Carlos cujo modelado constitui-se basicamente por colinas de topos convexos (Dc) e tabulares (Dt), apresentando formas de dissecação média, com vales entalhados e densidade de drenagem média a alta, o que implica, portanto em um nível de fragilidade potencial médio a baixo, para os terrenos poucos dissecados, alto a muito alto para os terrenos muito dissecados; e os Patamares Estruturais de Ribeirão Preto cujo modelado constitui-se basicamente por colinas amplas e baixas com topos tabulares (Dt), com os vales apresentando entalhamento médio com menos de 20m e a dimensão interfluvial varia de $750 \mathrm{~m}$ até mais de $3750 \mathrm{~m}$, apresentando formas de relevo pouco dissecado com vales pouco entalhados, com vertentes de declividades baixas e solos argilosos e baixa densidade de drenagem esta unidade apresenta fragilidade potencial muito baixa, ou seja, com baixo potencial erosivo.

$\mathrm{Na}$ área correspondente à subunidade Depressão Periférica Paulista, a bacia do Ribeirão das Pedras situa-se sobre a unidade morfológica denominada Depressão de Moji-Guaçu. Nesta unidade predominam formas de relevo denudacionais cujo modelado constitui-se basicamente por colinas de topos tabulares amplos, onde os vales são entalhados até $20 \mathrm{~m}$ e a dimensão interfluvial oscila entre 1750 a $3750 \mathrm{~m}$. A drenagem apresenta um padrão dendrítico com algum condicionamento estrutural. Por apresentar padrão de dissecação baixo com vales pouco entalhados e com densidade de drenagem baixa, esta unidade apresenta, em geral, um nível de fragilidade potencial muito baixo, com baixo potencial erosivo.

As cotas encontradas regionalmente situam-se entre 540 e $1.040 \mathrm{~m}$, com um desnível total de $500 \mathrm{~m}$ tendo como ponto mais alto o topo do Morro do Quadrão, com $1.042 \mathrm{~m}$ de altitude. Assim, os locais com altitudes mais elevadas localizam-se na porção sudoeste da área de estudo, regredindo em direção nordeste até atingir áreas de menores altitudes (540 m) na várzea do Rio Mogi-Guaçu.

De acordo com a classificação dada por Mendonça e Danni-Oliveira (2007), o tipo climático da região é Clima tropical do Brasil central sem seca. As chuvas ocorrem mais frequentemente no verão, porém a área apresenta clima úmido o ano todo. Os meses mais chuvosos estão entre outubro e março, destacando-se o período de dezembro a março com pluviosidade anual média de $1450 \mathrm{~mm}$.

Numa escala geológica continental, a área está inserida no domínio geológico denominado Cobertura Fanerozóica (inclusive da província sub-andina), na compartimentação geotectônica Cráton Paraná, na 
Província Estrutural do Paraná (HASUI, 2012). No que se refere a geologia regional, mapeada por BrasilDNPM (1979) na escala 1:250.000, estão distribuídas nessa área física, as seguintes unidades litológicas: lavas basálticas toleíticas (Formação Serra Geral, Triássico), arenitos médios a muito finos (Formação Pirambóia, Triássico) e argilitos, folhelhos e siltitos (Formação Corumbataí, Permiano).

De acordo com o mapeamento geológico (São Paulo-IG (1981), efetuado na escala 1:50.000, foram encontrados dois grupos estratigráficos principais: São Bento e Passa Dois. O Grupo São Bento é composto por Magmatitos Básicos Intrusivos (diabásio; JKmb) e pela Formação Pirambóia (arenitos fluviais; TrJp), enquanto que o Grupo Passa Dois é representado pela Formação Corumbataí (arenitos, siltitos, lamitos e folhelhos; Pc). Além disso, ocorrem materiais de idade terciária da Formação Pirassununga (areias e conglomerados; Tp) e Coberturas Inconsolidadas (depósitos aluviais, areias e argilas; Qa).

\section{CARACTERIZAÇÃO DA ÁREA DE ESTUDO}

Os planos de informação georreferenciados utilizados no trabalho foram elaborados utilizando o software ArcGIS ${ }^{\circledR} 10.2$ (ESRI, 2013). Para a montagem do banco de dados, foram utilizados seguintes documentos cartográficos: carta topográfica de Pirassununga (SF-23-V-C-V-3), produzida por Brasil - IBGE (1983), mapa das formações geológicas de superfície (SÃO PAULO-IG (1981) e mapa de materiais inconsolidados (GALIANO, 2001), todos na escala 1:50.000.

Rotta e Zuquette (2015) descrevem o escoamento superficial como o mais importante agente da erosão hídrica. A obtenção de dados de escoamento superficial pode se apoiar em distintas abordagens quanto ao enfoque dos atributos do meio e quanto à obtenção da informação de interesse.

Em alguns casos, dados locais e simulações de campo são utilizados para tal finalidade (FIGUEIREDO et al., 2016; SEIDL et al., 2020). Outras abordagens se valem da combinação de atributos ambientais para obtenção de cartas de escoamento superficial potencial (SANTOS; LOLLO, 2016; COSTA et al., 2018), e/ou da combinação dos atributos naturais na forma de Curva Número de referência (SARTORI et al., 2011; SANTOS; LOLLO, 2016).

Outra abordagem comum se baseia na consideração da importância de atributos específicos do meio, em particular o relevo (ZHANG et al., 2018; GHOMASH et al., 2019). No entanto, a consideração dos efeitos das mudanças de uso e cobertura tem sido a abordagem mais comum (FIGUEIREDO et al., 2016; SANTOS; LOLLO, 2016; YANG; LU, 2017; COSTA et al., 2018; SUN et al., 2018; FALCÃO et al., 2020, SEIDL et al., 2020).

Os documentos cartográficos geotécnicos específicos foram produzidos com base na metodologia elaborada por Pejon (1992), e detalhada em Pejon e Zuquette (2001).

Para a elaboração de uma carta temática é imprescindível, segundo Pejon (1992), o conhecimento adequado dos componentes do meio físico e seus atributos relevantes para o tema em análise. O autor destaca a importância das relações entre a infiltração e o escoamento superficial, que condicionam a disponibilidade de água que irá escoar superficialmente.

A elaboração da carta de escoamento superficial se baseou em Pejon e Zuquette (1993), a qual tem sido bastante adotada em território nacional em função da relativa facilidade de obtenção dos atributos necessários à sua aplicação, tendo sido desenvolvida a partir da ponderação apresentada na Tabela 1, considerando ainda índice de erodibilidade e outras características geotécnicas dos materiais inconsolidados. Os fatores intervenientes no processo erosivo foram hierarquizados conforme mostra a Tabela 2.

A álgebra de mapas em foi desenvolvida a partir de planos de informação em formato matricial com células de 10×10 m em Sistema de Projeção Universal Transverse Mercator (UTM), segundo o sistema de referenciamento geodésico brasileiro SIRGAS 2000 (IBGE 2005) na Zona 23S.

O tratamento dos dados e informações foi desenvolvido em X etapas: (1) aquisição de dados do meio físico e de caracterização geotécnica dos materiais inconsolidados; (2) ponderação das informações do item (1), segundo os pesos e valores constantes na Tabela 1; (3) produção da carta de escoamento superficial a partir da soma dos valores dos atributos na área; (4) produção da carta de risco potencial à erosão, conforme ponderação apresentada na Tabela 2 .

A caracterização geotécnica dos materiais inconsolidados foi fundamental não só para definição da 
influência de seus atributos no processo, mas para interpretação, em conjunto com os demais dados do meio físico, de processo erosivo na área.

Tabela 1 - Atributos do meio físico utilizados para a elaboração da carta potencial de escoamento superficial, (PEJON, 1992). OBS. Os números entre parênteses significam a pontuação atribuída àquele atributo na análise.

POTENCIAL DE ESCOAMENTO SUPERFICIAL AUMENTA

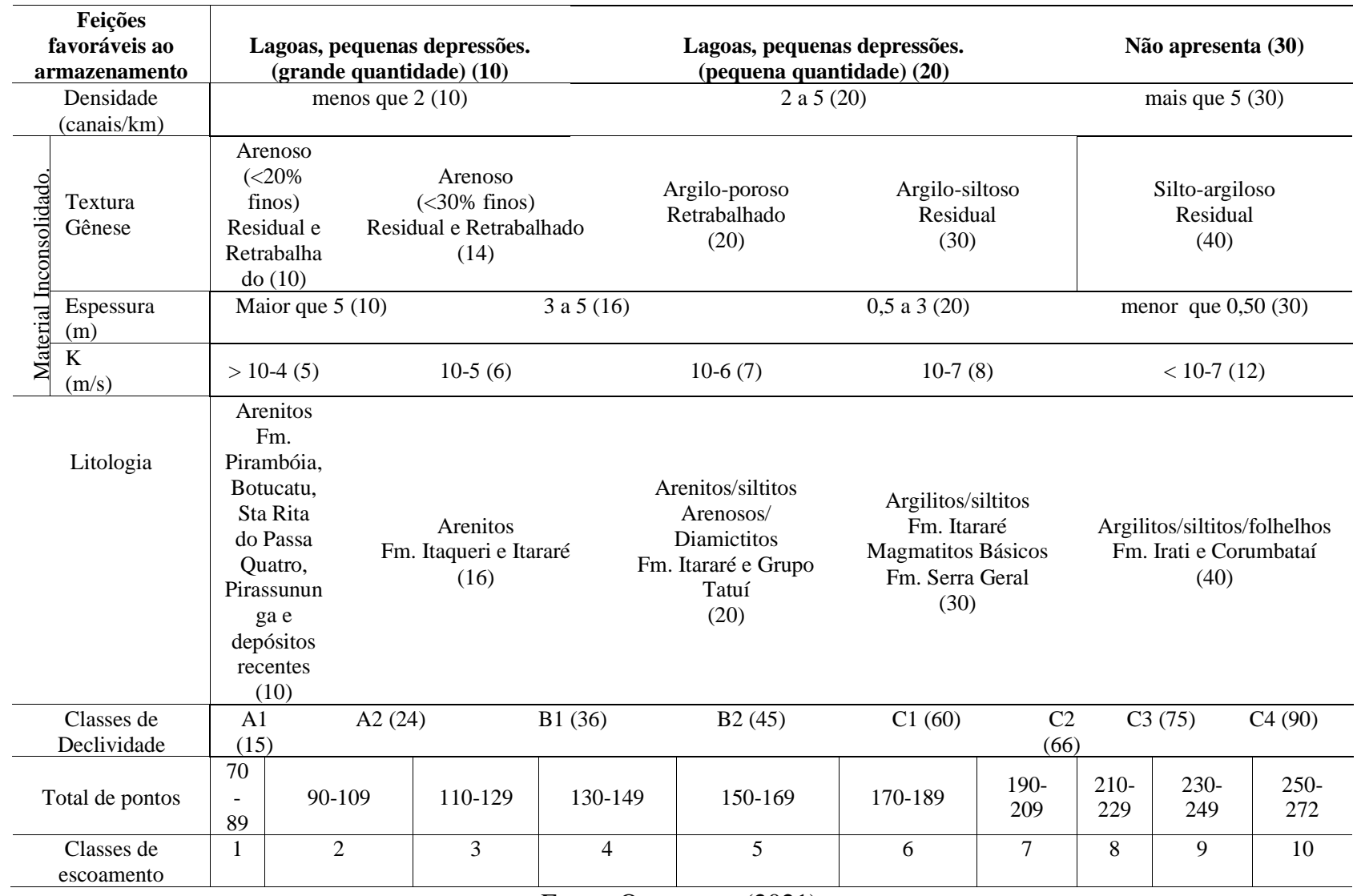

Fonte: Os autores (2021).

Tabela 2 - Pontuação dos atributos considerados na elaboração da carta de risco potencial à erosão (PEJON, 1992). OBS. Os números entre parênteses significam a pontuação atribuída àquele atributo na análise.

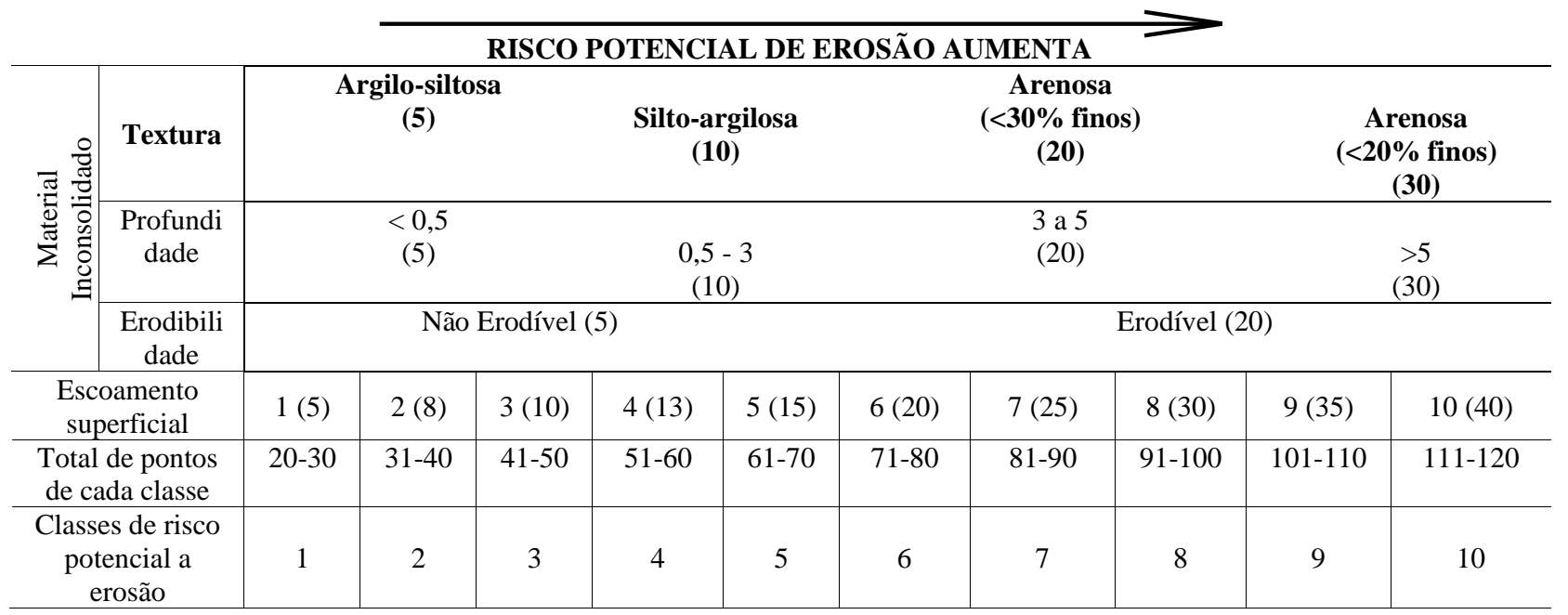

Fonte: Os autores (2021). 


\section{RESULTADOS E ANÁLISES}

\subsection{Caracterização dos materiais Inconsolidados}

\subsubsection{MATERIAL INCONSOLIDADO RESIDUAL DAS ROCHAS MAGMÁTICAS BÁSICAS INTRUSIVAS}

O material inconsolidado residual das rochas Intrusivas Básicas aparece em maior porcentagem na área mapeada, nas regiões mais planas, sua caracterização é sintetizada na Tabela 3 obtida de Galiano et al. (2016).

Tabela 3 - Caracterização geotécnica dos materiais inconsolidados residuais das rochas intrusivas básicas. Onde: Ar: Percentual de areia (fina+média+grossa); Si: Percentual de Silte; Ag: Percentual de Argila; ps: Massa específica do solo; Mini-MCV: Adaptação do ensaio MVC em corpos de prova de dimensões reduzidas; Pi: Indicação qualitativa de resistência à erosão hídrica; MCT: Mini-Compactação-Tropical; CTC: Capacidade de Troca de Cátions; K20: Razão entre a densidade relativa da água à temperatura $(\mathrm{t})$ e a densidade relativa da água a $20^{\circ} \mathrm{C}$. Mini-CBR - Ensaio CBR em

corpos de prova de dimensões reduzidas; Exp.: Expansão; Ret.: retração; MCT: Mini-Compactação-Tropical; pd: resistividade do solo; e0: índice de vazios; wot: Teor de umidade ótimo da curva de compactação.

\begin{tabular}{|c|c|c|c|c|c|c|c|c|c|}
\hline \multirow{2}{*}{$\operatorname{Amostra}\left(n^{0}\right)$} & \multirow{2}{*}{$\begin{array}{l}\text { Profundidade } \\
\text { (cm) }\end{array}$} & \multirow{2}{*}{$\begin{array}{l}\mathrm{Ar} \\
(\%)\end{array}$} & \multirow{2}{*}{$\begin{array}{l}\mathrm{Si} \\
(\%)\end{array}$} & \multirow{2}{*}{$\begin{array}{l}\mathrm{Ag} \\
(\%)\end{array}$} & \multirow{2}{*}{$\begin{array}{l}\rho \mathrm{\rho s} \\
(\mathrm{g} / \mathrm{cm} 3)\end{array}$} & \multicolumn{2}{|c|}{ Mini-MCV } & \multirow{2}{*}{$\begin{array}{l}\text { CTC } \\
(\mathrm{cmol}(+) / \mathrm{Kg})\end{array}$} & \multirow{2}{*}{$\begin{array}{l}\mathrm{K} 20 \\
(\mathrm{~cm} / \mathrm{seg}-1)\end{array}$} \\
\hline & & & & & & Pi \% & MCT & & \\
\hline $\mathrm{P} 4 \mathrm{~A}$ & 0,50 a 0,70 & 11 & 29 & 60 & 2,844 & 80,0 & LG' $^{\prime}$ & 9,2 & $2,91 \times 10-3$ \\
\hline P4B & 3,50 a 3,70 & 12 & 17 & 71 & 3,064 & 1,0 & LG' $^{\prime}$ & 11,0 & $3,96 \times 10-3$ \\
\hline P4C & 7,00 a 7,20 & 16 & 40 & 44 & 3,062 & 140,0 & $\mathrm{NS}^{\prime}$ & 18,4 & $4,91 \times 10-4$ \\
\hline
\end{tabular}

\begin{tabular}{|c|c|c|c|c|c|c|c|c|}
\hline \multirow[b]{2}{*}{$\operatorname{Amostra}\left(\mathbf{n}^{\mathbf{o}}\right)$} & \multirow[b]{2}{*}{$\begin{array}{l}\text { Profundidade } \\
\text { (cm) }\end{array}$} & \multicolumn{3}{|c|}{ Mini-CBR } & \multirow[b]{2}{*}{$\begin{array}{c}\rho d \\
(\mathrm{~g} / \mathrm{cm} 3)\end{array}$} & \multirow[b]{2}{*}{ e0 } & \multirow[b]{2}{*}{ wot. $(\%)$} & \multirow[b]{2}{*}{$\begin{array}{c}\text { Índice de } \\
\text { Erodibilidade }\end{array}$} \\
\hline & & Exp. & Ret. & MCT & & & & \\
\hline $\mathrm{P} 4 \mathrm{~A}$ & 0,50 a 0,70 & 0,1 & 2,3 & 8,0 & 1,58 & 0,80 & 28,0 & 9,98 \\
\hline $\mathrm{P} 4 \mathrm{~B}$ & 3,50 a 3,70 & 0,1 & 2,5 & 12,0 & 1,48 & 1,07 & 30,0 & 1,02 \\
\hline $\mathrm{P} 4 \mathrm{C}$ & 7,00 a 7,20 & 0,4 & 1,9 & 15,0 & 1,52 & 1,01 & 30,0 & 0,91 \\
\hline
\end{tabular}

Fonte: Galiano et al. (2016).

Representada na área por diabásios, encontra-se em uma área relativamente plana, recobrindo 74,6\% da área das rochas Intrusivas Básicas, O aparecimento de solos saprolíticos, observado nesta área de estudo pelo comportamento não laterítico, aumento do teor de silte e diminuição da permeabilidade, em pequenas profundidades, são indicativos do menor grau de decomposição da rocha basáltica, assim como o baixo grau de laterização. Seu intemperismo pode resultar na formação de pequenos blocos de argila, do tamanho de grãos de areia, denominados "pelts", que alteram o comportamento dos materiais inconsolidados, conferindo-lhes menor resistência. Por exemplo, a ocorrência de permeabilidades, em geral mais baixas, nos materiais inconsolidados residuais das rochas Intrusivas Básicas, em relação aos materiais inconsolidados de outras formações argilosas, como a Corumbataí. Os potenciais de erosão acelerada, levemente maiores que os esperados, encontrados neste mapeamento, podem ser decorrentes destes fatores.

\subsubsection{MATERIAIS INCONSOLIDADOS RETRABALHADOS DAS ROCHAS INTRUSIVAS BÁSICAS}

Os materiais classificados ocorrem principalmente nos vales das áreas desta formação geológica, e apresentaram características conforme a Tabela 4 obtida de Galiano et al. (2016). 
Tabela 4 - Caracterização geotécnica dos materiais retrabalhados das rochas intrusivas básicas. Onde: Ar: Percentual de areia (fina+média+grossa); Si: Percentual de Silte; Ag: Percentual de Argila; ps: Massa específica do solo; Mini-MCV: Adaptação do ensaio MVC em corpos de prova de dimensões reduzidas; Pi: Indicação qualitativa de resistência à erosão hídrica; MCT: Mini-Compactação-Tropical; CTC: Capacidade de Troca de Cátions; K20: Razão entre a densidade relativa da água à temperatura $(\mathrm{t})$ e a densidade relativa da água a $20^{\circ} \mathrm{C}$. Mini-CBR - Ensaio CBR em corpos de prova de dimensões reduzidas; Exp.: Expansão; Ret.: retração; MCT: Mini-Compactação-Tropical; pd: resistividade do solo; e0: índice de vazios; wot: Teor de umidade ótimo da curva de compactação.

\begin{tabular}{|c|c|c|c|c|c|c|c|c|c|}
\hline \multirow{2}{*}{$\operatorname{Amostra}\left(n^{0}\right)$} & \multirow{2}{*}{$\begin{array}{l}\text { Profundidade } \\
\text { (cm) }\end{array}$} & \multirow{2}{*}{$\begin{array}{l}\text { Ar } \\
(\%)\end{array}$} & \multirow{2}{*}{$\begin{array}{l}\mathrm{Si} \\
(\%)\end{array}$} & \multirow{2}{*}{$\begin{array}{l}\mathrm{Ag} \\
(\%)\end{array}$} & \multirow{2}{*}{$\begin{array}{l}\rho s \\
(\mathrm{~g} / \mathrm{cm} 3)\end{array}$} & \multicolumn{2}{|c|}{ Mini-MCV } & \multirow{2}{*}{$\begin{array}{l}\text { CTC } \\
(\mathrm{cmol}(+) / \mathrm{Kg})\end{array}$} & \multirow{2}{*}{$\begin{array}{l}\mathrm{K} 20 \\
(\mathrm{~cm} / \mathrm{seg}-1)\end{array}$} \\
\hline & & & & & & Pi \% & MCT & & \\
\hline P28A & 0,30 a 0,50 & 39 & 22 & 39 & 2,517 & 40,0 & $\mathrm{LG}^{\prime}$ & 16,5 & $6,22 \times 10-3$ \\
\hline $\mathrm{P} 28 \mathrm{~B}$ & 2,30 a 2,50 & 32 & 22 & 46 & 3,064 & 0,0 & $\mathrm{LG}^{\prime}$ & 12,8 & $2,95 \times 10-3$ \\
\hline P28C & 4,00 a 4,50 & 45 & 32 & 23 & 3,077 & 57,0 & $\mathrm{NG}^{\prime}$ & 16,5 & $1,25 \times 10-3$ \\
\hline
\end{tabular}

\begin{tabular}{|c|c|c|c|c|c|c|c|c|}
\hline \multirow[b]{2}{*}{$\operatorname{Amostra}\left(n^{0}\right)$} & \multirow[b]{2}{*}{$\begin{array}{l}\text { Profundidade } \\
\text { (cm) }\end{array}$} & \multicolumn{3}{|c|}{ Mini-CBR } & \multirow[b]{2}{*}{$\begin{array}{c}\rho d \\
(\mathrm{~g} / \mathrm{cm} 3)\end{array}$} & \multirow[b]{2}{*}{ e0 } & \multirow[b]{2}{*}{ wot. (\%) } & \multirow[b]{2}{*}{$\begin{array}{c}\text { Índice de } \\
\text { Erodibilidade }\end{array}$} \\
\hline & & Exp. & Ret. & MCT & & & & \\
\hline $\mathrm{P} 28 \mathrm{~A}$ & 0,30 a 0,50 & 0,1 & 2,1 & 14,7 & 1,40 & 0,80 & 27,0 & 69,02 \\
\hline P28B & 2,30 a 2,50 & 0,1 & 1,4 & 16,0 & 1,56 & 0,96 & 28,0 & 3,46 \\
\hline P28C & 4,00 a 4,50 & 0,1 & 0,6 & 18,3 & 1,49 & 0,59 & 29,0 & $*$ \\
\hline
\end{tabular}

Fonte: Galiano et al. (2016).

\subsubsection{MATERIAIS INCONSOLIDADOS RESIDUAIS DA FORMAÇÃO CORUMBATAÍ}

Os materiais inconsolidados, existentes neste grupo, perfazem aproximadamente $90 \%$ da área da formação geológica e tem seus atributos indicados na Tabela 5 obtida de Galiano et al. (2016).

Tabela 5 - Caracterização geotécnica dos materiais residuais da Fm. Corumbataí. Onde: Ar: Percentual de areia (fina+média+grossa); Si: Percentual de Silte; Ag: Percentual de Argila; $\rho$ s: Massa específica do solo; Mini-MCV: Adaptação do ensaio MVC em corpos de prova de dimensões reduzidas; Pi: Indicação qualitativa de resistência à erosão hídrica; MCT: Mini-Compactação-Tropical; CTC: Capacidade de Troca de Cátions; K20: Razão entre a densidade relativa da água à temperatura $(\mathrm{t})$ e a densidade relativa da água a $20^{\circ} \mathrm{C}$. Mini-CBR - Ensaio $\mathrm{CBR}$ em corpos de prova de dimensões reduzidas; Exp.: Expansão; Ret.: retração; MCT: Mini-Compactação-Tropical; $\rho$ d: resistividade do solo; e0: índice de vazios; wot: Teor de umidade ótimo da curva de compactação.

\begin{tabular}{|c|c|c|c|c|c|c|c|c|c|}
\hline \multirow{2}{*}{ Amostra (no) } & \multirow{2}{*}{$\begin{array}{l}\text { Profundidade } \\
(\mathrm{cm})\end{array}$} & \multirow{2}{*}{$\begin{array}{l}\mathrm{Ar} \\
(\%)\end{array}$} & \multirow{2}{*}{$\begin{array}{l}\mathrm{Si} \\
(\%)\end{array}$} & \multirow{2}{*}{$\begin{array}{l}\mathrm{Ag} \\
(\%)\end{array}$} & \multirow{2}{*}{$\begin{array}{l}\rho \mathrm{\rho s} \\
(\mathrm{g} / \mathrm{cm} 3)\end{array}$} & \multicolumn{2}{|c|}{ Mini-MCV } & \multirow{2}{*}{$\begin{array}{l}\text { CTC } \\
(\mathrm{cmol}(+) / \mathrm{Kg})\end{array}$} & \multirow{2}{*}{$\begin{array}{l}\text { K20 } \\
\text { (cm/seg-1) }\end{array}$} \\
\hline & & & & & & Pi \% & MCT & & \\
\hline P23A & 0,20 a 0,40 & 29,0 & 29,0 & 42,0 & 2,731 & 0,0 & $\mathrm{LG}^{\prime}$ & 23,9 & $2,13 \times 10-7$ \\
\hline $\mathrm{P} 23 \mathrm{~B}$ & 2.50 a 2.70 & 30,0 & 29,0 & 41,0 & 2,758 & 3,0 & LG' $^{\prime}$ & 33,0 & $6,24 \times 10-7$ \\
\hline $\mathrm{P} 23 \mathrm{C}$ & 4,00 a 4,20 & 11,0 & 52,0 & 37,0 & 2,706 & 320,0 & $\mathrm{NG}^{\prime}$ & 22,0 & $7,08 \times 10-8$ \\
\hline \multirow[b]{2}{*}{$\operatorname{Amostra}\left(\mathbf{n}^{0}\right)$} & \multirow[b]{2}{*}{$\begin{array}{l}\text { Profundidade } \\
\text { (cm) }\end{array}$} & \multicolumn{3}{|c|}{ Mini-CBR } & & \multirow{2}{*}{\multicolumn{2}{|c|}{ e0 }} & \multirow[b]{2}{*}{ wot. $(\%)$} & \multirow[b]{2}{*}{$\begin{array}{c}\text { Índice de } \\
\text { Erodibilidade }\end{array}$} \\
\hline & & Exp. & Ret. & MCT & $\begin{array}{c}\rho d \\
(\mathrm{~g} / \mathrm{cm} 3) \\
\end{array}$ & & & & \\
\hline $\mathrm{P} 23 \mathrm{~A}$ & 0,20 a 0,40 & 0,2 & 2,2 & \begin{tabular}{|l|}
11,2 \\
\end{tabular} & 1,52 & 0,79 & & 24,8 & 29,85 \\
\hline P23B & 2.50 a 2.70 & 0,1 & 1,8 & 12,5 & 1,44 & 0,91 & & 27,0 & 1,82 \\
\hline $\mathrm{P} 23 \mathrm{C}$ & 4,00 a 4,20 & 0,37 & 0,8 & 10,0 & 1,36 & 0,98 & & 29,0 & 2,47 \\
\hline
\end{tabular}

Fonte: Galiano et al. (2016).

\subsubsection{MATERIAIS INCONSOLIDADOS RETRABALHADOS DA FORMAÇÃO CORUMBATAÍ}

Tais materiais inconsolidados ocorrem nos vales de vertentes inclinadas, nas áreas mais baixas da região mapeada, apresentaram comportamento laterítico e textura silto-arenosos e areno-siltosos. Apresentaram permeabilidade baixa a muito baixa, massa específica seca obtida com o proctor normal variando de 1,36 a $1,75 \mathrm{~g} / \mathrm{cm} 3$, com umidade variando de 16 a $24 \%$, nas camadas superiores, e de 25 a $29 \%$ nas camadas mais profundas, CTC do solo com índices de 5,5 a 33,0 cmol+/Kg, e índice de erodibilidade maior que 1.

\subsubsection{MATERIAIS INCONSOLIDADOS RESIDUAIS DA FORMAÇÃO PIRAMBÓIA}

Esses materiais ocorrem somente nas áreas mais planas e de topos de colinas recobrindo os arenitos 
desta formação (Tabela 6) obtida de Galiano et al. (2016).

Tabela 6 - Caracterização geotécnica dos materiais inconsolidados residuais da Fm. Pirambóia. Onde: Ar: Percentual de areia (fina+média+grossa); Si: Percentual de Silte; Ag: Percentual de Argila; $\rho$ s: Massa específica do solo; Mini-MCV: Adaptação do ensaio MVC em corpos de prova de dimensões reduzidas; Pi: Indicação qualitativa de resistência à erosão hídrica; MCT: Mini-Compactação-Tropical; CTC: Capacidade de Troca de Cátions; K20: Razão entre a densidade relativa da água à temperatura $(\mathrm{t})$ e a densidade relativa da água a $20^{\circ} \mathrm{C}$. Mini-CBR - Ensaio CBR em corpos de prova de dimensões reduzidas; Exp.: Expansão; Ret.: retração; MCT: Mini-Compactação-Tropical; pd: resistividade do solo; e0: índice de vazios; wot: Teor de umidade ótimo da curva de compactação;

\begin{tabular}{|c|c|c|c|c|c|c|c|c|c|}
\hline \multirow{2}{*}{$\operatorname{Amostra}\left(n^{0}\right)$} & \multirow{2}{*}{$\begin{array}{l}\text { Profundidade } \\
\text { (cm) }\end{array}$} & \multirow{2}{*}{$\begin{array}{l}\mathrm{Ar} \\
(\%)\end{array}$} & \multirow{2}{*}{$\begin{array}{l}\mathrm{Si} \\
(\%)\end{array}$} & \multirow{2}{*}{$\begin{array}{l}\mathrm{Ag} \\
(\%)\end{array}$} & \multirow{2}{*}{$\begin{array}{l}\rho s \\
(\mathrm{~g} / \mathrm{cm} 3)\end{array}$} & \multicolumn{2}{|c|}{ Mini-MCV } & \multirow{2}{*}{$\begin{array}{l}\text { CTC } \\
(\mathrm{cmol}(+) / \mathrm{Kg})\end{array}$} & \multirow{2}{*}{$\begin{array}{l}\mathrm{K} 20 \\
(\mathrm{~cm} / \mathrm{seg}-1)\end{array}$} \\
\hline & & & & & & Pi \% & MCT & & \\
\hline P9A & 0,40 a 0,60 & 62,0 & 16,0 & 22,0 & 2,738 & 142,0 & LA' $^{\prime}$ & 5,5 & $1,17 \times 10-3$ \\
\hline P9B & 4,00 a 4,20 & 54,0 & 24,0 & 22,0 & 2,774 & 120,8 & $\mathrm{LA}^{\prime}$ & 0,0 & $2,30 \times 10-3$ \\
\hline
\end{tabular}

\begin{tabular}{|c|c|c|c|c|c|c|c|c|}
\hline \multirow[b]{2}{*}{$\operatorname{Amostra}\left(\mathbf{n}^{0}\right)$} & \multirow[b]{2}{*}{$\begin{array}{l}\text { Profundidade } \\
\text { (cm) }\end{array}$} & \multicolumn{3}{|c|}{ Mini-CBR } & \multirow[b]{2}{*}{$\begin{array}{c}\rho d \\
(\mathrm{~g} / \mathrm{cm} 3)\end{array}$} & \multirow[b]{2}{*}{ e0 } & \multirow[b]{2}{*}{ wot. (\%) } & \multirow[b]{2}{*}{$\begin{array}{c}\text { Índice de } \\
\text { Erodibilidade }\end{array}$} \\
\hline & & Exp. & Ret. & MCT & & & & \\
\hline P9A & 0,40 a 0,60 & 0,1 & 0,7 & 11,5 & 1,84 & 0,49 & 14,0 & 61,77 \\
\hline P9B & 4,00 a 4,20 & 0,1 & 1,2 & 13,0 & 1,87 & 0,48 & 15,0 & $*$ \\
\hline
\end{tabular}

Fonte: Galiano et al. (2016).

\subsubsection{MATERIAIS INCONSOLIDADOS RESIDUAIS DA FORMAÇÃO PIRAMBÓIA}

A maior parte das áreas de ocorrência da Formação Pirambóia apresenta-se recoberta com materiais inconsolidados retrabalhados, cujas características geotécnicas estão sintetizadas na Tabela 7 obtida de Galiano et al. (2016).

Tabela 7 - Caracterização geotécnica dos materiais retrabalhados da Fm. Pirambóia.Onde: Ar: Percentual de areia (fina+média+grossa); Si: Percentual de Silte; Ag: Percentual de Argila; $\rho$ s: Massa específica do solo; Mini-MCV: Adaptação do ensaio MVC em corpos de prova de dimensões reduzidas; Pi: Indicação qualitativa de resistência à erosão hídrica; MCT: Mini-Compactação-Tropical; CTC: Capacidade de Troca de Cátions; K20: Razão entre a densidade relativa da água à temperatura $(\mathrm{t})$ e a densidade relativa da água a $20^{\circ} \mathrm{C}$. Mini-CBR - Ensaio CBR em corpos de prova de dimensões reduzidas; Exp.: Expansão; Ret.: retração; MCT: Mini-Compactação-Tropical; pd: resistividade do solo; e0: índice de vazios; wot: Teor de umidade ótimo da curva de compactação.

\begin{tabular}{|c|c|c|c|c|c|c|c|c|c|}
\hline \multirow{2}{*}{ Amostra (n') } & \multirow{2}{*}{$\begin{array}{l}\text { Profundidade } \\
(\mathrm{cm})\end{array}$} & \multirow{2}{*}{$\begin{array}{l}\text { Ar } \\
(\%)\end{array}$} & \multirow{2}{*}{$\begin{array}{l}\text { Si } \\
(\%)\end{array}$} & \multirow{2}{*}{$\begin{array}{l}\mathrm{Ag} \\
(\%)\end{array}$} & \multirow{2}{*}{$\begin{array}{l}\rho s \\
(\mathrm{~g} / \mathrm{cm} 3)\end{array}$} & \multicolumn{2}{|c|}{ Mini-MCV } & \multirow{2}{*}{$\begin{array}{l}\text { CTC } \\
(\operatorname{cmol}(+) / K g)\end{array}$} & \multirow{2}{*}{$\begin{array}{l}\mathrm{K} 20 \\
(\mathrm{~cm} / \mathrm{seg}-1)\end{array}$} \\
\hline & & & & & & $\mathbf{P i} \%$ & MCT & & \\
\hline P22A & 0,40 a 0,60 & 44 & 15 & 41 & 2,794 & 30,0 & $\mathrm{LG}^{\prime}$ & 29,4 & $8,22 \times 10-3$ \\
\hline $\mathrm{P} 22 \mathrm{~B}$ & 2,30 a 2,50 & 37 & 19 & 44 & 2,889 & 0,0 & $\mathrm{LG}^{\prime}$ & 36,7 & $1,84 \times 10-3$ \\
\hline P22C & 4,00 a 4,20 & 90 & 4 & 6 & 2,652 & $*$ & NA & 5,5 & $1,57 \times 10-3$ \\
\hline
\end{tabular}

\begin{tabular}{|c|c|c|c|c|c|c|c|c|}
\hline \multirow[b]{2}{*}{$\operatorname{Amostra}\left(\mathbf{n}^{\circ}\right)$} & \multirow[b]{2}{*}{$\begin{array}{l}\text { Profundidade } \\
(\mathrm{cm})\end{array}$} & \multicolumn{3}{|c|}{ Mini-CBR } & \multirow[b]{2}{*}{$\begin{array}{c}\rho d \\
(\mathrm{~g} / \mathrm{cm} 3)\end{array}$} & \multirow[b]{2}{*}{ e0 } & \multirow[b]{2}{*}{ wot. (\%) } & \multirow[b]{2}{*}{$\begin{array}{c}\text { Índice de } \\
\text { Erodibilidade }\end{array}$} \\
\hline & & Exp. & Ret. & MCT & & & & \\
\hline $\mathrm{P} 22 \mathrm{~A}$ & 0,40 a 0,60 & 0,15 & 1,40 & 11,0 & 1,71 & 0,63 & $20,5 \%$ & 219,40 \\
\hline $\mathrm{P} 22 \mathrm{~B}$ & 2,30 a 2,50 & 0,06 & 2,35 & 16,0 & 1,58 & 0,82 & $25,5 \%$ & 0,95 \\
\hline P22C & 4,00 a 4,20 & $*$ & $*$ & $*$ & $*$ & $*$ & $*$ & 302,96 \\
\hline
\end{tabular}

Fonte: Galiano et al. (2016).

\subsubsection{MATERIAIS INCONSOLIDADOS RETRABALHADOS DA FORMAÇÃO PIRASSUNUNGA}

Esses materiais ocorrem em grande parte da área bacia, em particular nos extensos topos planos da planície do rio Mogi Guaçu, e suas propriedades são apresentadas na Tabela 8 obtida de Galiano et al. (2016). São essencialmente areias lateríticas de baixa compacidade.

Ocasionalmente podem apresentar porcentagens altas de finos, com acréscimo de areia em profundidade, o que pode refletir a contribuição das intrusivas básicas em sua origem. 
Tabela 8 - Caracterização geotécnica dos materiais inconsolidados retrabalhados da Fm. Pirassununga. Onde: Ar: Percentual de areia (fina+média+grossa); Si: Percentual de Silte; Ag: Percentual de Argila; $\rho s:$ Massa específica do solo; Mini-MCV: Adaptação do ensaio MVC em corpos de prova de dimensões reduzidas; Pi: Indicação qualitativa de resistência à erosão hídrica; MCT: Mini-Compactação-Tropical; CTC: Capacidade de Troca de Cátions; K20: Razão entre a densidade relativa da água à temperatura $(\mathrm{t})$ e a densidade relativa da água a $20^{\circ} \mathrm{C}$. Mini-CBR - Ensaio CBR em corpos de prova de dimensões reduzidas; Exp.: Expansão; Ret.: retração; MCT: Mini-Compactação-Tropical; $\rho d$ :

\begin{tabular}{|c|c|c|c|c|c|c|c|c|c|}
\hline \multirow{2}{*}{$\operatorname{Amostra}\left(n^{0}\right)$} & \multirow{2}{*}{$\begin{array}{l}\text { Profundidade } \\
(\mathrm{cm})\end{array}$} & \multirow{2}{*}{$\begin{array}{l}\mathrm{Ar} \\
(\%)\end{array}$} & \multirow{2}{*}{$\begin{array}{l}\mathrm{Si} \\
(\%)\end{array}$} & \multirow{2}{*}{$\begin{array}{l}\mathrm{Ag} \\
(\%)\end{array}$} & \multirow{2}{*}{$\begin{array}{l}\rho s \\
(\mathrm{~g} / \mathrm{cm} 3)\end{array}$} & \multicolumn{2}{|c|}{ Mini-MCV } & \multirow{2}{*}{$\begin{array}{l}\text { CTC } \\
(\mathrm{cmol}(+) / \mathrm{Kg})\end{array}$} & \multirow{2}{*}{$\begin{array}{l}\text { K20 } \\
\text { (cm/seg-1) }\end{array}$} \\
\hline & & & & & & Pi \% & MCT & & \\
\hline P19A & 0,40 a 0,60 & 86 & 4 & 10 & 2,662 & 260,0 & NA & 5,5 & $2,30 \times 10-2$ \\
\hline P19B & 3,40 a 3,60 & 83 & 5 & 12 & 2,675 & 227,0 & NA & 9,2 & $1,93 \times 10-2$ \\
\hline P19C & 5,30 a 5,50 & 84 & 4 & 12 & 2,671 & 220,0 & NA & 7,3 & $1,69 \times 10-2$ \\
\hline
\end{tabular}

\begin{tabular}{|c|c|c|c|c|c|c|c|c|}
\hline \multirow[b]{2}{*}{$\operatorname{Amostra}\left(\mathbf{n}^{\mathbf{0}}\right)$} & \multirow[b]{2}{*}{$\begin{array}{l}\text { Profundidade } \\
\text { (cm) }\end{array}$} & \multicolumn{3}{|c|}{ Mini-CBR } & \multirow[b]{2}{*}{$\begin{array}{c}\rho d \\
(\mathrm{~g} / \mathrm{cm} 3)\end{array}$} & \multirow{2}{*}{ e0 } & \multirow{2}{*}{ wot. $(\%)$} & \multirow[b]{2}{*}{$\begin{array}{c}\text { Índice de } \\
\text { Erodibilidade }\end{array}$} \\
\hline & & Exp. & Ret. & MCT & & & & \\
\hline P19A & 0,40 a 0,60 & 0,1 & 0,1 & 9,0 & 1,90 & 0,40 & $11,0 \%$ & 15,15 \\
\hline P19B & 3,40 a 3,60 & 0,0 & 0,0 & 13,0 & 1,96 & 0,40 & $9,5 \%$ & 0,34 \\
\hline P19C & 5,30 a 5,50 & 0,5 & 0,2 & 13,0 & 1,92 & 0,39 & $9,0 \%$ & 0,44 \\
\hline
\end{tabular}

Fonte: Galiano et al. (2016).

\subsubsection{MATERIAIS INCONSOLIDADOS DOS SEDIMENTOS DO QUATERNÁRIO}

As amostras de materiais inconsolidados das áreas de aluvião foram coletadas em locais mais altos, onde inundações sazonais ocorreriam somente em grandes cheias.

Os materiais originários das áreas de aluvião apresentam textura arenosa, com menos de $30 \%$ de finos, permeabilidade média, massa específica seca, obtida com o proctor normal variando de 1,84 a 1,96 g/cm3, com umidade ótima em média $24,7 \%$, CTC do solo com resultados que variam de 5,5 a 9,2 cmol+/Kg.

\subsection{Escoamento Superficial "versus" materiais Inconsolidados}

A carta de escoamento superficial da bacia mostra dois grandes grupos que coincidem com as parcelas do terreno relacionadas com as duas principais unidades morfoestruturais presentes na área, que são o Planalto Ocidental e a Depressão Periférica Paulista. A não ocorrência das classes 9 e 10 de escoamento se deu em função de não ter sido registradas na área associação de valores dos atributos que resultassem pontuações de escoamento superficial na faixa 230-272.

As áreas de maior escoamento superficial são as parcelas de solo da formação Corumbataí, na porção norte da área, coincidindo com o relevo mais acidentado e maiores declividades do terreno (Figura 1).

As classes de menor escoamento superficial estão sobre os terrenos da Formação Pirassununga, predominantemente arenosa, e a maior parte desta formação encontra-se sobre a região da subunidade morfoescultural, denominada Depressão de Mogi Guaçu em áreas com menores declividades. 
Figura 1 - Carta de potencial ao escoamento superficial da Bacia Hidrográfica do ribeirão das Pedras (SP).

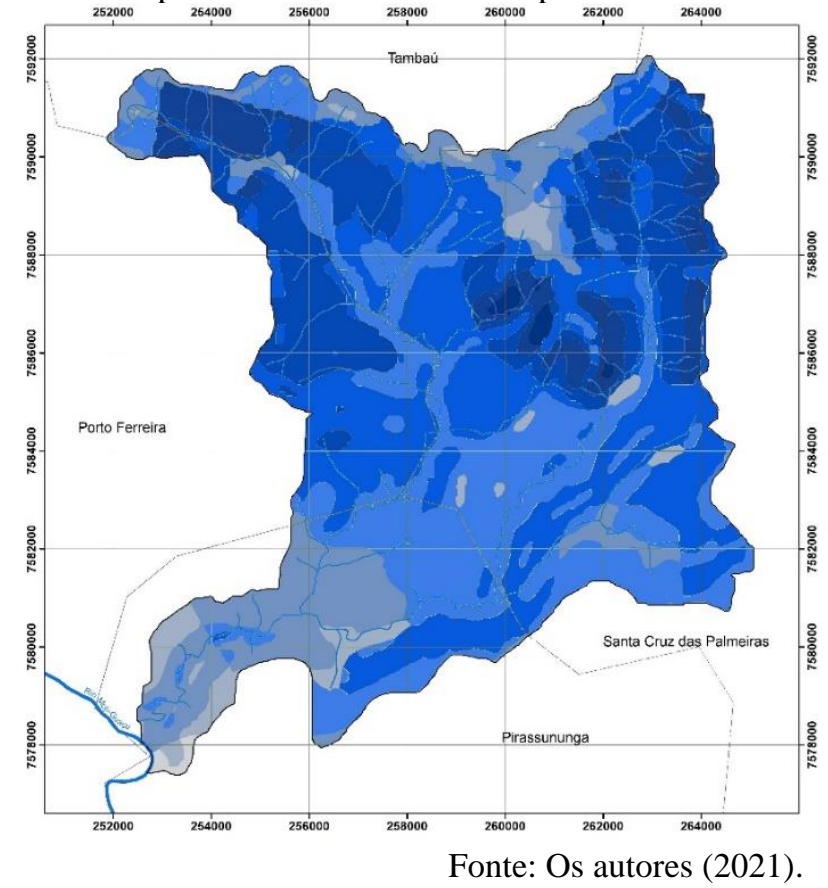
Legenda

ì: Limite de Município

3 Bacia Hidrográfica

? Hidrografia

Potencial de Escoamento Superficial

Classe 1

Classe 2

Classe 3

Classe 4

Classe 6

Classe 7

Classe 8

$w \stackrel{1}{N}$

Escala Numérica: 1:150.000

$\begin{array}{llll}0 & 1.25 & 2.5 & 5 \mathrm{Km}\end{array}$

Sistema de Projeção: UTM Zona: $23 \mathrm{~S}$

Sistema de Referência: SIRGAS2000

Fonte: Mapeamento Geotécnico da

Quadrícula de Pirassununga como

subsídio ao desenvolvimento regional.

\subsection{Carta de Potencial de Erosão Acelerada}

Combinando-se os atributos dos materiais inconsolidados e de escoamento superficial potencial, se obteve a distribuição espacial para Potencial de Erosão Acelerada apresentada na Figura 2.

Figura 2 - Carta de potencial de risco à erosão acelerada da Bacia Hidrográfica do Ribeirão das Pedras (SP).

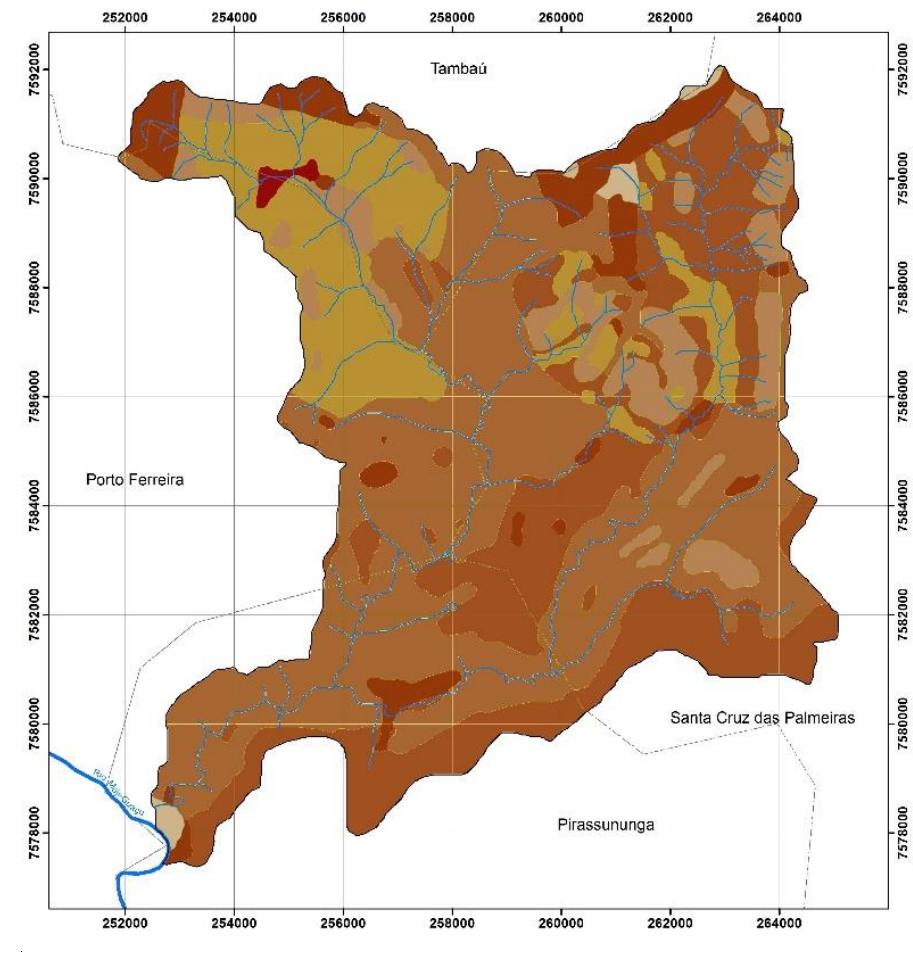

Legenda

ì? Limite de Município

3 Bacia Hidrográfica

: $\sim$ Hidrografia

Potencial Erosão

Classe 2

Classe 3

Classe 4

Classe 5

Classe 6

Classe 7

Classe 8

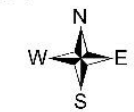

Escala Numérica: 1:150.000

$\begin{array}{llll}0 & 1.25 & 2.5 & 5 \mathrm{Km}\end{array}$

Sistema de Projeção: UTM

Zona: $23 S$

Sistema de Referência: SIRGAS2000

Fonte: Mapeamento Geotécnico da

Quadrícula de Pirassununga como

subsídio ao desenvolvimento regional.

Fonte: Os autores (2021).

Visando embasar as discussões dos resultados obtidos à luz das condições do meio físico da bacia do Ribeirão das Pedras, são apresentados os mapas das Unidades Litológicas (Figura 3) de Materiais Inconsolidados (Figura 4). 
Figura 3 - Mapa Geológico para a Bacia Hidrográfica do Ribeirão das Pedras (SP).

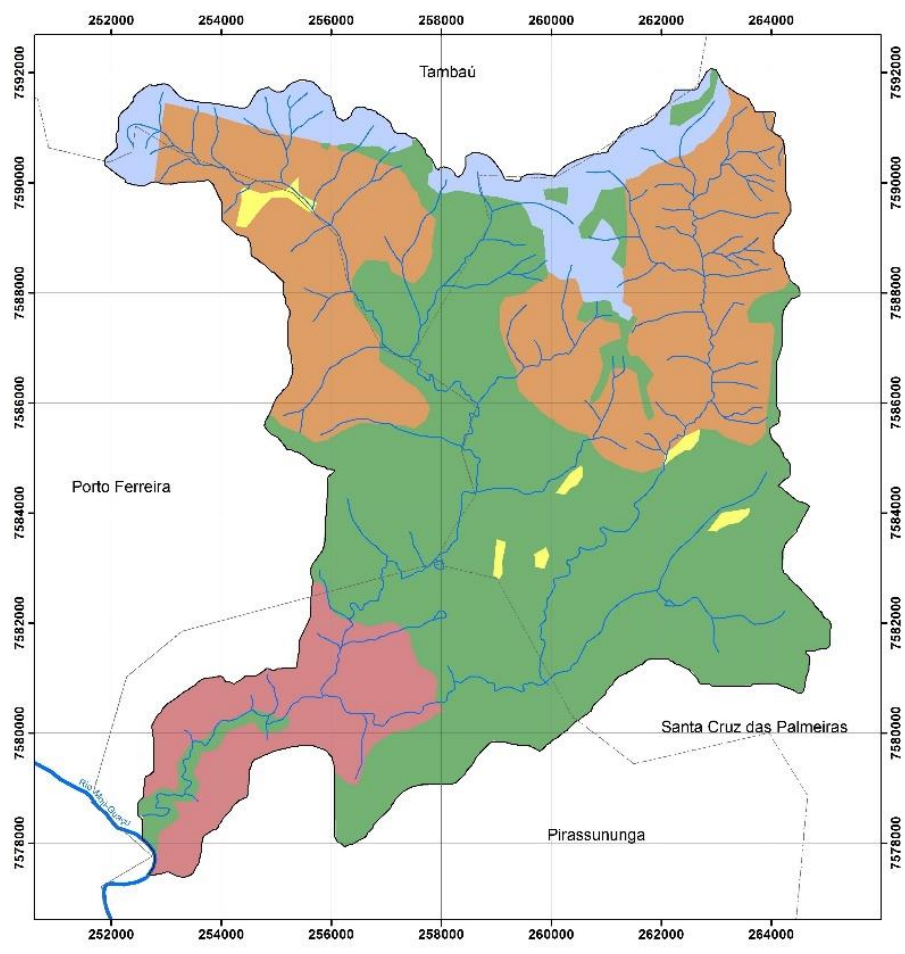

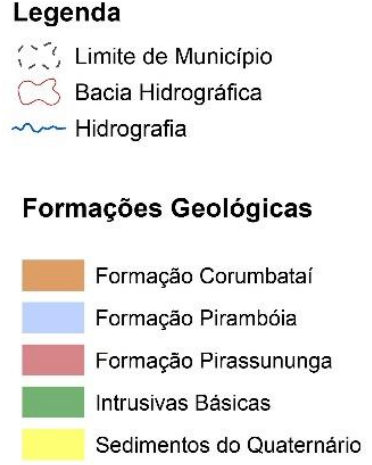

$\therefore$ Limite de Município

3 Bacia Hidrográfica

$\sim$ Hidrografia

\section{Formações Geológicas}

Formação Corumbataí

Formação Pirambóia

Formação Pirassununga

Intrusivas Básicas

Sedimentos do Quaternário

Escala Numérica: 1:150.000

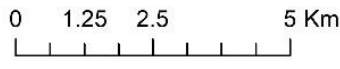

Sistema de Projeção: UTM Zona: $23 S$

Sistema de Referência: SIRGAS2000

Fonte: Mapeamento Geotécnico da

Quadrícula de Pirassununga como

subsidio ao desenvolvimento regional.

Fonte: Galiano (2001).

Figura 4 - Mapa de Materiais Inconsolidados para a Bacia Hidrográfica do Ribeirão das Pedras (SP).

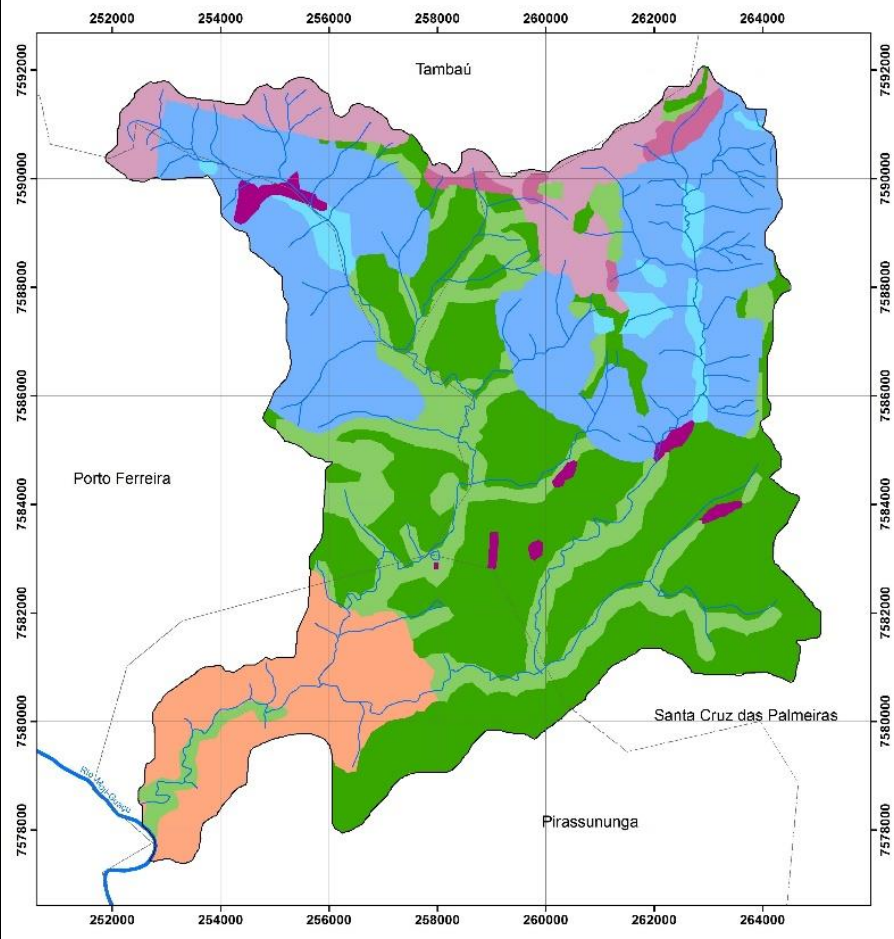

Fonte: Galiano (2001).

\section{Legenda}

¿', Limite de Município

$\widetilde{3}$ Bacia Hidrográfica

? Hidrografia

\section{Material Inconsolidado}

Residual das Intrusivas Básicas

Retrabalhado das Intrusivas Básicas

Residual da Formação Corumbatal

Retrabalhado da Formação Corumbatai

Residual da Formação Pirambóia

Retrabalhado da Formaçăo Pirambóia

Retrabalhado da Formaçăo Pirassununga

Aluviozes

$$
w \overbrace{S}^{N}-E
$$

Escala Numérica: 1:150.000

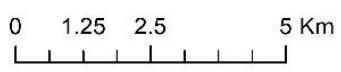

Sistema de Projeção: UTM Zona: $23 S$

Sistema de Referência: SIRGAS2000

Fonte: Mapeamento Geotécnico da

Quadricula de Pirassununga como

subsídio ao desenvolvimento regional.

Inicialmente, merece destaque o fato que áreas nas quais se obteve classes de potencial de escoamento superficial muito alto ( 6 a 8 ) resultaram classificadas como potencial erosivo baixo ( 2 a 4$)$. Tal condição ocorre porque nas áreas de escoamento superficial muito alto, resultado influenciado pela declividade, os materiais inconsolidados predominantes apresentam textura fina a média, perfis com menores espessuras, e condição "não erodível".

Em adição à tal informação, Ghomash et al. (2019) mostram que no início do escoamento superficial, os efeitos são mais evidentes nas áreas de relevo mais suave, e Zhang et al. (2018) não identificaram relação 
direta entre declividade e escoamento, e destacaram que os efeitos da declividade no escoamento tendem a diminuir a partir de $15^{\circ}$, sendo tal efeito mais notado nas áreas solos rasos ou substrato rochoso exposto.

Merece destaque a não ocorrência das classes 1, 9, e 10 de potencial de erosão acelerada. A existência de tais classes na área seria resultado de uma combinação extremamente favorável (classe 1) ou extremamente desfavorável (classes 9 e 10) dos fatores considerados.

No primeiro caso, se teria uma combinação de declividades muito baixas, com materiais inconsolidados com características de perfil de alteração, textura e estrutura que resultam condições não erodíveis; enquanto no segundo caso a classificação seria resultado da ocorrência de materiais inconsolidados com textura arenosa, estrutura fofa e perfis espessos combinados com altas declividades.

A não ocorrência de tais combinações na bacia do Ribeirão das Pedras é reflexo do ambiente geológico e, como consequência, dos perfis de solos formados.

Como se pode observar na Figura 5-, a classe mais prevalente de risco à erosão acelerada é a classe 5 $(48,92 \%)$, seguida da classe $6(28,14 \%)$, o que demonstra que a área estudada apresenta potenciais medianos a altos de erosão acelerada.

Figura 5 - Percentual das classes de potencial de risco à erosão acelerada da bacia hidrográfica do Ribeirão das Pedras (SP).

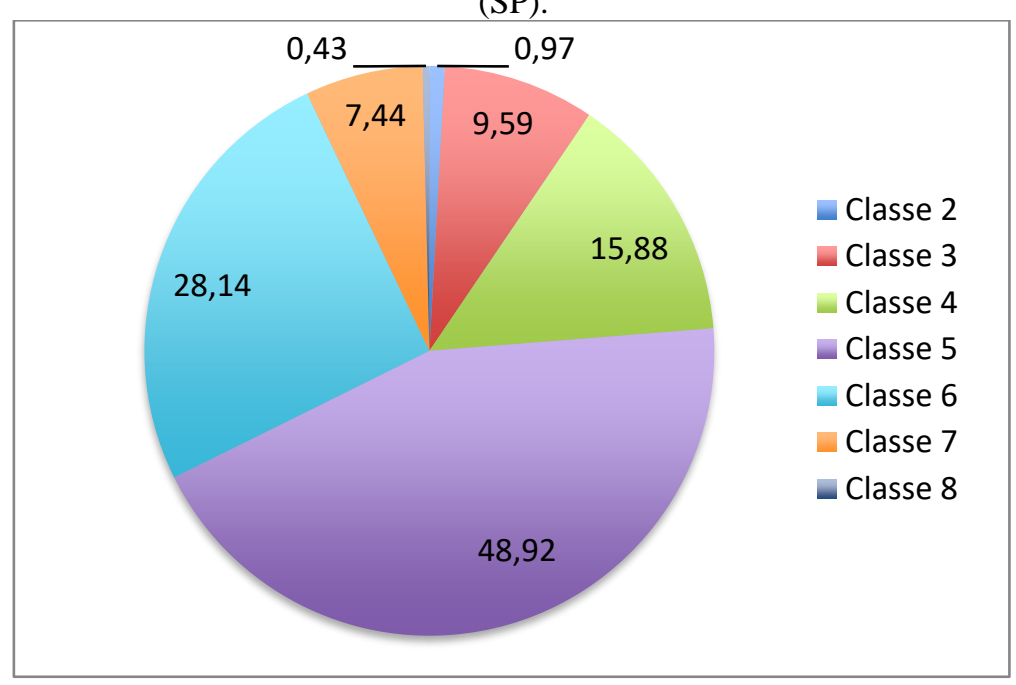

Fonte: Os autores (2021).

A não ocorrência das classes 9 e 10 de escoamento se deu em função de não ter sido registradas na área associação de valores dos atributos que resultassem pontuações de escoamento superficial na faixa 230272, pressuposto do método usado para que tais classes sejam identificadas.

Interessante observar que Figueiredo et al. (2016), Yang e Lu (2017), Sun et al. (2018), Falcão et al. (2020), e Seidl et al. (2020); destacam as mudanças de uso e cobertura e o sistema radicular das espécies vegetais presentes na área, como fatores determinantes nas condições de escoamento superficial após o estabelecimento do fluxo difuso na superfície. Assim, o entendimento completo dos processos, e a relação com a erosão, são únicos, e devem ser analisados com cuidado em cada caso.

De outra parte, Santos; Lollo (2016) e Costa et al. (2018) mostram a ocorrência de processos erosivos em áreas classificadas como baixo escoamento superficial potencial, condicionados pelas condições texturais e estruturais dos materiais inconsolidados, pela ação humana, e por variações locais do relevo, tais como quebras de relevo em áreas de cabeceiras de drenagem.

\section{CONCLUSÕES}

A carta de risco potencial à erosão obtida reflete os atributos do meio físico da bacia mais significativos no condicionamento dos processos erosivos, podendo vir a ser um documento muito útil para o planejamento da Bacia do Ribeirão das Pedras.

Mesmo não exibindo as classes de escoamento superficial mais elevadas (9 e 10), a bacia apresenta 
classes de erosão potencial intermediárias a altas predominando, como consequência da ocorrência de perfis de materiais inconsolidados arenosos, espessos e de baixa compacidade, que condicionam o potencial erosivo.

As áreas que apresentam condições de relevo condicionando maiores escoamento superficial, por outro lado, apresentam materiais inconsolidados com texturas, espessuras e consistência que não condicionam os processos erosivos.

A caracterização geotécnica as unidades de materiais inconsolidados foi fundamental para tal entendimento, por permitir o conhecimento das características de seus perfis, como a classificação dos mesmo em termos de erodibilidade. As unidades de textura arenosa (em particular, Pirassununga e Pirambóia) condicionam maiores potenciais para desenvolvimento de erosão acelerada. Algumas porções apresentam classe 8 de potencial à erosão acelerada combinada com áreas de intensa expansão urbana, merecendo especial atenção.

Os resultados obtidos confirmam a importância da avaliação de cada área como única ao se analisar as condições para desenvolvimento de processos erosivos, aspecto já destacada por trabalhos recentes indicados no texto.

\section{Agradecimentos}

Os autores agradecem a Fundação de Amparo à Pesquisa do Estado de São Paulo (FAPESP), pela concessão de recursos financeiros, aportados ao Processo $n^{\circ}$. 2013/03699-5, os quais possibilitaram a geração de resultados laboratoriais essenciais na elaboração deste trabalho e informam que "o presente trabalho foi realizado com apoio da Coordenação de Aperfeiçoamento de Pessoal de Nível Superior - Brasil (CAPES) Código de Financiamento 001".

\section{Contribuição dos Autores}

O Primeiro autor do Manuscrito, Valdir Aparecido Galiano desenvolveu a cartografia básica e a caracterização geotécnica dos materiais, participou da elaboração da primeira versão do texto do artigo. $\mathrm{O}$ segundo autor, Reinaldo Lorandi foi o supervisor da pesquisa e também responsável pela obtenção dos recursos, e participou de todas as etapas de coleta e interpretação dos dados, e da redação final do artigo;

A terceira autora Franciane Mendonça dos Santos apoiou a análise dos dados e desenvolvimento de produtos cartográficos interpretativos, participou da redação final e das etapas de revisão do artigo e o quarto autor, José Augusto Di Lollo, participou do planejamento do artigo, da coleta e análise dos dados, bem como da redação final e das etapas de revisão do artigo;

\section{Conflitos de Interesse}

Os autores declaram que não há conflitos de interesse.

\section{Referências}

BIELENKI, C. J.; BARBASSA, A. P. Geoprocessamento e recursos hídricos: aplicações práticas. São Carlos: EdUFSCar, 2012.

BRASIL. Instituto Brasileiro de Geografia e Estatística. Folha topográfica de Piraçununga (SF-23-V-C-V3). São Paulo: IBGE, 1983. Escala 1:50.000.

CHRISTOFOLETTI, A. Geomorfologia. São Paulo: Editora da Universidade de São Paulo, 1974. 149p.

COSTA, C. W.; LORANDI, R.; DI LOLLO, J. A.; IMANI, M.; DUPAS, F. A. Surface runoff and accelerated erosion in a peri-urban wellhead area in southeastern Brazil. Environmental earth sciences, v. 77, n.5, p. 160, 2018. DOI.: 10.1007/s12665-018-7366-x

ESRI, ArcGIS Desktop. Redlands, CA; 2013. 
FALCÃO, K. D. S.; PANACHUKI, E.; MONTEIRO, F. D. N.; DA SILVA MENEZES, R.; RODRIGUES, D. B.; SONE, J. S.; OLIVEIRA, P. T. S. Surface runoff and soil erosion in a natural regeneration area of the Brazilian Cerrado, International soil and water conservation research. v.8, n.2, p. 124-13, 2020. DOI. DOI.: 10.1016/j.iswcr.2020.04.004

FAO (Food and Agriculture Organization of the United Nations). The state of the world's land and water resources for food and agriculture (SOLAW) - Managing systems at risk. London: Food and Agriculture Organization of the United Nations, 2011.

FEITOSA, F. A. C. Hidrogeologia: conceitos e aplicações. Rio de Janeiro: CPRM: LABHID, 2008. 812p.

FIGUEIREDO, J. V.; ARAÚJO, J. C.; MEDEIROS, P. H. A.; COSTA, A. C. Runoff initiation in a preserved semiarid Caatinga small watershed, Northeastern Brazil. Hydrological Processes, v. 30, n. 1, p. 23902400, 2016. DOI.: 10.1002/hyp.10801

FOLLEY, J. A.; DEFRIES, R.; ASNER, G. P.; BARFORD, C.; BONAN, G.; CARPENTER, S. R.; CHAPIN, F. S.; COEL, M. T.; DAILY, G. C.; GIBBS, H. K.; HELKOWSKI, J. H.; HOLLOWAY, T.; HOWARD, E. A.; KUCHARIK, C. J.; MONDREDA, C.; PATZ, J. A.; PRENTICE, C.; RAMANKUTTY, N.; SNYDER, P. K. Global Consequences of Land Use. Science, v. 309, n. 5734, p. 570-574, 2005. DOI: 10.1126/science. 1111772

FRANZ, B. Fatores Intervenientes nas vulnerabilidades dos recursos hídricos às mudanças do clima no Estado do Rio de Janeiro. In: Nunes, R. T. S.; Freitas, M. A. V.; Rosa, L. P. Vulnerabilidade dos recursos hídricos no âmbito regional e urbano. Rio de Janeiro: Interciência, 2011, p.3-60.

GALIANO, V. A. Mapeamento geotécnico da quadrícula de Pirassununga (SP) na escala 1:50.000, como subsídio ao planejamento do meio físico. 140p. Dissertação (Mestrado) - PPG-Engenharia, Universidade Federal de São Carlos, São Carlos, 2001.

GALIANO, V. A.; LORANDI, R.; LOLLO, J. A. Proposta de ordenamento territorial da bacia hidrográfica do Rio das Pedras (SP), na escala 1:50.000: potencial à escavabilidade dos maciços de solos. Revista de Geología Aplicada a la Ingeniería y al Ambiente, v. 36, p. 29-39, 2016.

GHOMASH, S. K. B.; CAVIEDES-VOULLIEME, D.; HINZ, C. Effects of erosion-induced changes to topography on runoff dynamics. Journal of Hydrology, v. 573, p. 811-828, 2019. DOI: 10.1016/j.jhydrol.2019.04.018

GUPTA, A.; AHMAD, R. Urban steeplands in tropics: an environment of accelerated erosion. GeoJournal, v. 49, p. 143-150, 1996.

HASUI, Y. Compartimentação Geológica do Brasil in Geologia do Brasil. São Paulo: Beca, 2012.

HE, X; ZHOU, J; ZHANG, X; TANG, K. Soil erosion response to climatic change and human activity during the Quaternary of the Loess Plateau, China. Regional Environment Change, v. 6, n. 1-2, p. 62-70, 2006. DOI.: 10.1007/s10113-005-0004-7

KEMP, K. Environmental Modeling with GIS: A Strategy for Dealing with Spatial Continuity. Tese (Doutorado). University of California, Santa Barbara, 1992.

LOURES, S. S. P.; CALIJURI, M. L.; GUIMARÃES, A. O. Sistemas de gerenciamento de dados para bacias hidrográficas urbanas. In: Simpósio Brasileiro de Cartografia Geotécnica e Geoambiental, 5., 2004. São Carlos. Anais...Suprema Gráfica Editora, 2004. p. 477-483.

MENDONÇA, F.; DANNI-OLIVEIRA, I. M. Climatologia: noções básicas e climas do Brasil. São Paulo: Oficina de Textos, 2007.

MORAES, A. C. R. Ordenamento territorial: uma Conceituação para o Planejamento Estratégico. In: Ministério da Integração Nacional. Para pensar uma política nacional de ordenamento territorial: Anais da Oficina sobre a Política Nacional de Ordenamento Territorial, Brasília: MI, 2005. p. 13-14.

OLIVEIRA, H. H. de. Proposta de criação e caracterização da Área de Proteção Ambiental de Descalvado, SP. Dissertação (Mestrado em Ciências) - Instituto de Biociências, Universidade de São Paulo, São Paulo, 1995. 
OLIVEIRA, K. A. Ordenamento territorial e bacias hidrográficas: um estudo sobre os projetos do Comitê PCJ. Fórum Ambiental da Alta Paulista, v. 6, p. 114-123, 2010.

PEJON, O. J. Mapeamento geotécnico da Folha de Piracicaba-SP (Escala 1:100.000): estudo de aspectos metodológicos, de caracterização e de apresentação de atributos. 224f. Tese (Doutorado), Universidade de São Paulo, São Carlos, 1992.

PEJON, O. J.; ZUQUETTE, L. V. Carta do Potencial à erosão acelerada por escoamento concentrado. In: Congresso Brasileiro de Geologia de Engenharia, 7., 1993, Poços de Caldas. Anais...ABGE, 1993. p. 245254.

PEJON, O. J.; ZUQUETTE, L. V. Carta de predisposição a erosão acelerada - área de Piracicaba, Estado de São Paulo, Brasil: Metodologia e Avaliação dos resultados. Geotecnia, v. 93, p. 33-60, 2001.

PIMENTEL, D. Soil erosion: a food and environmental threat. Environment, Development and Sustainability, v. 8, p. 119-137, 2006. DOI.: 10.1007/s10668-005-1262-8

ROTTA, C. M. S.; ZUQUETTE, L. V. Processos erosivos. In: Zuquette, L. V. Geotecnia ambiental, Rio de Janeiro, Elsevier, 2015. p. 115-152.

ROSS, J. L. S.; MOROZ, I. C. Mapa Geomorfológico do Estado de São Paulo. São Paulo: Laboratório de Cartografia Geotécnica. 1997. vol. 1 e 2. 64p.

SANTOS, F. M.; LOLLO, J. A. Low cost potential infiltration estimation for wet tropical watersheds for territorial planning support. Journal of Urban and Environmental Engineering, v. 10, n. 2, p. 233-241, 2016. DOI.: 10.4090/juee.2016.v10n2.233241.

SARTORI, A.; HAWKINS, R. H.; GENOVEZ, A. M. Reference curve numbers and behavior for sugarcane on highly weathered tropical soils. Journal of irrigation and drainage engineering, v. 137, n. 11, p. 705711, 2011. DOI.: 10.1061/(ASCE)IR.1943-4774.0000354.

IG. INSTITUTO GEOLÓGICO. Formações Geológicas de Superfície. Folha de Piraçununga (SF-23-V-CV-3). São Paulo: IG, 1981.

SÃO PAULO. Macrozoneamento das Bacias dos Rios Mogi Guaçu, Pardo e Médio Grande: Questões sócio ambientais e regionais. São Paulo: Secretaria do Meio Ambiente, Secretaria da Agricultura e Abastecimento e Secretaria de Economia e Planejamento, 1995.

ROCHA, G. (Coord.) Mapa de águas subterrâneas do Estado de São Paulo: escala 1:1.000.000, nota explicativa. São Paulo: DAEE/IG/IPT/CPRM, 2005, 119 p.

SÃO PAULO - FEHIDRO. Plano da Bacia Hidrográfica: 2008-2011. Comitê da Bacia Hidrográfica do Rio Mogi Guaçu, 170p, 2011.

SEIDL, M.; HADRICH, B.; PALMIER, L.; PETRUCCI, G.; NASCIMENTO, N. Impact of urbanisation (trends) on runoff behaviour of Pampulha watersheds (Brazil). Environmental Science and Pollution Research, v. 27, p.14259-14270, 2020. DOI.: 10.1007/s11356-019-06029-6

SILVA, R. M.; SANTOS, C. A. G.; SILVA, V. C. L. SILVA, L. P. Erosivity, surface runoff, and soil erosion estimation using GIS-coupled runoff-erosion model in the Mamuaba catchment, Brazil. Environmental Monitoring and Assessment, v. 185, n.11, p. 8977-8990, 2013. DOI.: 10.1007/s10661-013-3228-x

STRAHLER, A. N. Hypsometric (area-altitude) analysis of erosional topography. Geological Society of America Bulletin, v. 63, n. 11, p. 1117-1142, 1952. DOI.: 10.1130/00167606(1952)63[1117:HAAOET]2.0.CO;2

SUN, D.; YANG, H.; GUAN, D.; YANG, M.; WU, J.; YUAN, F.; ZHANG, Y. The effects of land use change on soil infiltration capacity in China: A meta-analysis. Science of the Total Environment, v. 626, p. 1394-1401, 2018. DOI.: 10.1016/j.scitotenv.2018.01.104

TOREZAN, F. E. Análise ambiental da Bacia do Rio Bonito (Descalvado, SP) com ênfase nas atividades de exploração mineral de areia. 165p. Dissertação de Mestrado, Universidade Federal de São Carlos, São Carlos, 2000.

VENTE, J., POESEN, J., VERSTRAETEN, G., GOVERS, G., VANMAERCKE, M., ROMPAEY, A. V., 
ARABKHEDRI, M., BOIX-FAYOS, C. Predicting soil erosion and sediment yield at regional scales: Where do we stand? Earth-Science Reviews, v. 127, p. 16-29, 2013. DOI.: 10.1016/j.earscirev.2013.08.014

VITOUSEK, P. M.; MOONEY, H. A.; LUBCHENCO. J.; MELILLO, J. M. Human Domination of Earth's. Ecosystems. Science, v. 277, n. 5325, p. 494-499, 1997. DOI.: 10.1126/science.277.5325.494

YANG, K.; LU, C. Evaluation of land-use change effects on runoff and soil erosion of a hilly basin - the Yanhe River in the Chinese Loess Plateau. Land Degradation \& Development, v. 29, n. 4, p. 1211-1221, 2018. DOI.: $10.1002 / \mathrm{ldr} .2873$

YANG, Q. MENG, F.R.; ZHAO, Z.; CHOW, T.L.; BENOY, G.; REES, H.W.; BOURQUE, C.P.A. Assessing the impacts of flow diversion terraces on stream water and sediment yields at a watershed level using SWAT model. Agriculture, Ecosystems \& Environment, v. 132, n. 1-2, p. 23-31, 2009. DOI.: 10.1016/j.agee.2009.02.012

ZHANG, Xingqi et al. Effects of topographic factors on runoff and soil loss in Southwest China. Catena, v. 160, p. 394-402, 2018. DOI.: 10.1016/j.catena.2017.10.013

ZHAO, G., MU, X., WEN, Z., WANG, F. GAO, P. Soil erosion, conservation, and eco-environment changes in the loess Plateu of China. Land Degradation \& Development, v. 24, n. 5, p. 499-510, 2013. DOI.: $10.1002 /$ ldr.2246.

\section{Biografia do autor principal}

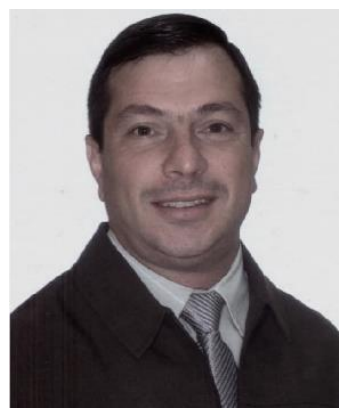

\footnotetext{
Nascido em Santa Cruz das Palmeiras - SP em 1965, formado em engenharia civil com habilitação em agrimensura na FEAP em Pirassununga - SP, mestre em Engenharia Urbana pela UFSCAR, na área de mapeamento geológico geotécnico para desenvolvimento urbano-regional. Coordenador de cursos de engenharia, orientador de projetos integradores interdisciplinares. Membro do Grupo de Geologia do Planejamento do Meio Físico na UFSCar. Artigos publicados nas áreas de geoprocessamento e geotecnologias. Professor Universitário e consultor para projetos e obras de infraestrutura na empresa Onsite Engenharia \& Consultoria Ltda em São Paulo - SP.
} 